\title{
Les tourteaux d'oléagineux, source de protéines en alimentation animale
}

Jacques EVRARD

\section{CETIOM, Direction scientifique,} Transformation et valorisation des graines Rue Monge, Parc industriel 33600 Pessac. Tél. : 05560730 84, Fax.0556079718 <evrard@cetiom.fr>

\begin{abstract}
The part of rapeseed and sunflower in total french consumption of meals has strongly increased during these twenty last years. Financial support for extensive research work on rapeseed and sunflower meal coming mainly from farmers organizations and french government allowed many animal trials in experimental stations and in feedstuffs companies, leading to a better knowledge of these meals in comparison of soyabean meal. The composition and nutritional parameters are now well known but these meals are not yet sufficiently used. Progress in using these protein sources will be possible by an increased knowledge of raw materials available on the market, by taking in account additional parameters for formulating feedstuffs and finally by further gains of quality in oilseeds
\end{abstract}

Key words: rapeseed, sunflower, soyabean, protein, meals, feedstuffs

tion totale de tourteaux en 2003 contre $86 \%$ en 1981.

Les efforts consentis jusqu'au début des années 90 par l'interprofession oléoprotéagineuse, en collaboration avec l'INRA, les instituts techniques et les principaux fabricants d'aliments du bétail, ont permis d'établir les caractéristiques nutritionnelles et les recommandations d'emploi des tourteaux de colza et de tournesol, disponibles sur le marché, dans l'alimentation des animaux monogastriques (porcs et volailles notamment) et des ruminants.

Par ailleurs, le souci de performance zootechnique au sens strict (indice de consommation, gain moyen quotidien, niveaux de production, etc.) a progressivement intégré d'autres aspects de la performance, notamment la qualité des produits animaux et la maîtrise des rejets occasionnés par les pratiques d'élevage.

\section{Caractéristiques analytiques et nutritionnelles}

Comparativement au tourteau de soja, source azotée de référence en alimentation animale, les tourteaux de colza et de tournesol sont moins riches en protéines et plus riches en cellulose brute (tableau 1). Le tourteau de colza est cependant bien équilibré en acides aminés limitants primaires (lysine, méthionine) alors que le soja est déficient en méthionine, le tournesol étant quant à lui carencé en lysine. La concentration en lysine et méthionine digestibles du colza est élevée et proche des seuils recommandés pour les vaches laitières. Enfin, le tourteau de colza est riche en calcium et phosphore.

\section{Facteurs antinutritionnels}

\section{Glucosinolates du colza}

Les produits de dégradation des glucosinolates sont responsables de problèmes d'appétence et de désordres physiologiques chez les ruminants et les animaux monogastriques. Chez les ruminants, l'inappétence peut aussi être due aux fines présentes dans les tourteaux de colza non granulés. Le progrès génétique permet de disposer sur le marché de colzas à faible teneur en glucosinolates dont les teneurs se situent en moyenne aux alentours de $15 \mu$ moles $/ g$ de graines (figure 1); les teneurs en glucosinolates

Tableau 1. Composition moyenne des tourteaux.

\begin{tabular}{|lcccc|}
\hline & Colza & Tournesol non décortiqué & Tournesol décortiqué & Soja 48 \\
\hline Protéines (\% produit brut) & 34 & 29 & 33 & 45 \\
Cellulose (\% produit brut) & 12 & 24 & 21 & 6 \\
Matière grasse (\%) & 2,3 & 1,9 & 1,7 & 1,9 \\
Calcium (g/kg) & 8,3 & 3,9 & 4,1 & 3,4 \\
Phosphore (g/kg) & 11,4 & 10,1 & 10,8 & 6,2 \\
Lys disponible (\% PDIE) & 6,8 & 5,9 & 5,8 & 6,9 \\
Met disponible (\% PDIE) & 2,0 & 2,1 & 2,1 & $-1,5$ \\
Glucosinolates ( $\mu$ moles/g MS) & $5-20^{\text {a }}$ & - & - & - \\
\hline
\end{tabular}

Source : base de données lo7 - Association Française de Zootechnie.

a Enquête qualité CETIOM-ONIDOL 2004. 


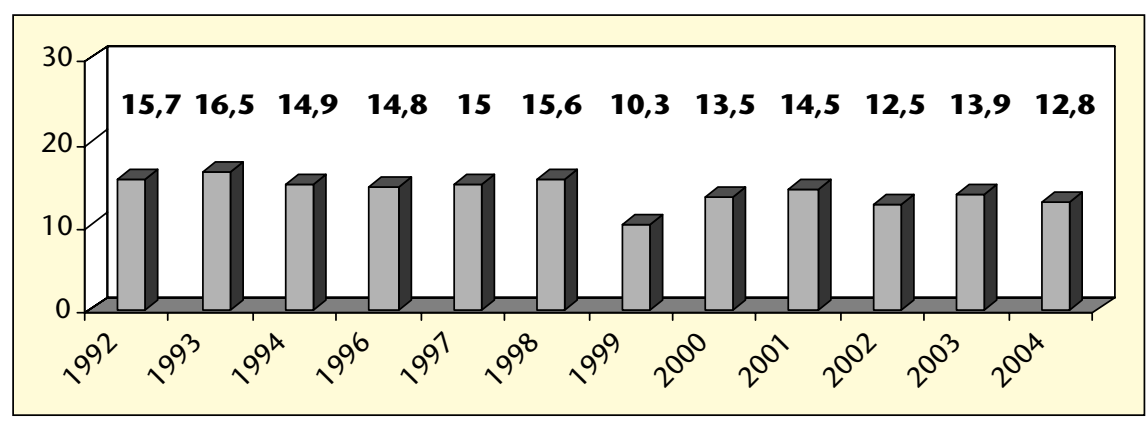

Figure 1. Teneur en glucosinolates des graines de colza depuis 1993 ( $\mu$ moles/g de graines). Source : enquête qualité CETIOM-ONIDOL.

des tourteaux produits dans les huileries françaises sont comprises entre 5 et $20 \mu$ moles $/ g$.

\section{Sinapine du colza}

La sinapine est un composé phénolique dont le métabolisme chez certaines espèces de poules pondeuses produit une odeur de poisson dans les œufs. Aucun programme d'abaissement de la teneur en sinapine du colza n'a été entrepris à ce jour.

\section{Facteurs antitrypsiques du soja}

Les facteurs antitrypsiques naturellement présents dans les graines de soja sont détruits en partie par les traitements thermiques pratiqués au cours de l'extraction de I'huile.

Le tournesol ne contient pas de facteurs antinutritionnels.
La teneur élevée en cellulose et lignines (concentrées dans les coques entourant les graines) et la composition glucidique des parois cellulaires, dans le cas du colza, réduisent la digestibilité et l'utilisation métabolique des protéines de colza et de tournesol chez les animaux monogastriques (porcs et volailles) avec pour conséquences des pertes d'azote dans l'environnement. Les traitements thermiques pratiqués au cours de la trituration des graines peuvent également altérer la digestibilité des protéines.

La dégradabilité ruminale élevée de l'azote des tourteaux de colza et de tournesol (tableau 2) se traduit, chez les ruminants, par des valeurs PDI inférieures à celles du tourteau de soja. Le tannage des tourteaux diminue la dégradabilité de l'azote et augmente les valeurs PDI. Le tannage est classiquement réalisé par action du formaldéhyde; des traitements thermiques adaptés au cours de la trituration des graines oléagineuses produisent des effets analogues et font actuellement l'objet d'études d'optimisation (CETIOM-CREOL-ONIDOL).

La cellulose, les lignines et certains polysaccharides contenus dans les parois cellulaires du colza réduisent également les valeurs énergétiques des tourteaux de colza et de tournesol (tableau 3).

De nombreux travaux ont été réalisés (dépelliculage du colza dans les années 80 , décorticage du tournesol au début des années 90) pour réduire la teneur en cellulose et lignine des graines et accroitre ainsi la valeur énergétique des tourteaux. Cependant, les premiers développements industriels mis en place n'ont pas démontré la rentabilité de ces technologies. Une seule usine produit en France du tourteau de tournesol partiellement décortiqué (Auvergne Trituration - Lezoux - Puy-deDôme); du tourteau partiellement décortiqué est importé d'Argentine.

\section{Usages actuels}

Aujourd'hui, les tourteaux de colza et de tournesol représentent chacun $4 \%$ environ des matières premières utilisées en alimentation animale, le tourteau de soja représentant $15 \%$

Tableau 2. Dégradabilité ruminale et valeurs PDI (protéines digestibles dans l'intestin) des tourteaux.

\begin{tabular}{|lcccccc|}
\hline g/kg produit brut & Colza & Colza tanné & Tournesol entier & Tournesol décortiqué & Soja 48 & Soja 48 tanné \\
\hline DT (\%) & 69 & - & 77 & 77 & 63 & - \\
PDIN & 219 & 255 & 178 & 219 & 331 & 374 \\
PDIE $^{2}$ & 138 & 246 & 93 & 115 & 229 & 339 \\
\hline
\end{tabular}

Source : INRA. 1. Ration déficitaire en azote dégradable. 2. Ration limitée en énergie disponible pour la synthèse microbienne.

Tableau 3. Valeurs énergétiques des tourteaux.

\begin{tabular}{|lcccc|}
\hline & Colza & Tournesol non décortiqué & Tournesol décortiqué & Soja 48 \\
\hline $\begin{array}{l}\text { Energie brute } \\
\text { Energie }\end{array}$ & 4100 & 4100 & 4150 & 4180 \\
$\begin{array}{l}\text { métabolisable } \\
\text { volaille }\end{array}$ & 1500 & 1370 & 2220 & 2300 \\
$\begin{array}{l}\text { Energie } \\
\text { digestible }\end{array}$ & 2900 & & & 2440 \\
$\begin{array}{l}\text { porcs } \\
\text { Energie nette }\end{array}$ & 1450 & 2030 & & 3400 \\
$\begin{array}{l}\text { porcs } \\
\text { UFL (par kg) }\end{array}$ & 0,85 & 1060 & 1260 & 1680 \\
UFV (par kg) & 0,80 & 0,56 & 0,66 & 1,06 \\
\hline
\end{tabular}

Source : base de données lo7 - Association Française de Zootechnie.

${ }^{\mathrm{a}} \mathrm{kcal} / \mathrm{kg}$ de produit brut. 
Tableau 4. Répartition par espèces des usages de tourteaux de colza et tournesol en aliments composés.

\begin{tabular}{|lcc|}
\hline 2003-2004 & Colza & Tournesol \\
\hline Ruminants & $61 \%$ & $70 \%$ \\
Volailles & $9-10 \%$ & $10 \%$ \\
& & $\begin{array}{c}10 \text { (pondeuses) } \\
\text { Porcs }\end{array}$ \\
autres & $27 \%$ & $5 \%$ \\
Total & $100 \%$ & $15 \%$ (lapins) \\
& $=790000 \mathrm{t}$ & $=690000 \mathrm{t}$ \\
\hline
\end{tabular}

Source : modèle Prospective Aliment du CEREOPA.

Tableau 6. Limites maximales d'incorporation en usage chez les $F A B$.

\begin{tabular}{|lc|}
\hline Formules & Limites maximales (\%) \\
\hline Ruminants & $10-20$ \\
Porcs charcutiers & 5 \\
Truies & 5 \\
Poulets standard & 5 \\
Poulets label & 5 \\
Pondeuses & $2-3$ \\
Lapins & $10-20$ \\
\hline
\end{tabular}

environ du total. Les volumes de tourteaux de colza et de tournesol utilisés en alimentation animale s'accroissent mais l'augmentation des importations de tourteaux de soja consécutive à l'interdiction, en fin d'année 2000, des co-produits animaux accroît le déficit en protéines en France et en Europe.

D'une façon générale, les tourteaux de colza et de tournesol sont principalement utilisés dans I'alimentation des ruminants (tableau 4), sans problèmes techniques majeurs d'incorporation. Les monogastriques (porcs et volailles) constituent un marché d'opportunité ; il persiste encore des freins techniques à leur utilisation: faible digestibilité de l'énergie et des protéines, facteurs antinutritionnels résiduels.

\section{Tourteau de colza}

La consommation française de tourteaux de colza est estimée, en 2004, à 940000 t, dont 790000 t incorporées dans les aliments composés par les fabricants d'aliments du bétail (FAB) et 150000 t utilisées en fabrication d'aliments à la ferme (FAF). Pour mémoire, les
Tableau 5. Limites maximales d'incorporation chez les monogastriques.

\begin{tabular}{|lc|}
\hline Formules & Limites maximales (\%) \\
\hline Porcs charcutiers & 6 \\
Porcelets & 0 \\
Truies & 0 \\
Poulets standard & 8 \\
Poulets label & 4 \\
Pondeuses & 0 \\
\hline
\end{tabular}

Source : modèle Prospective Aliment du CEREOPA.

usages de tourteaux de soja en fabrication $\mathrm{d}^{\prime}$ aliments à la ferme représentent entre 1,2 et 1,3 Mt.

Les usages de tourteaux de colza pour la fabrication d'aliments à la ferme se développent actuellement, notamment en production vaches laitières, mais aussi en production porcs.

L'usage des tourteaux de colza dans I'alimentation des vaches laitières se fait essentiellement sous forme tannée (60\% des tourteaux sont tannés), selon le ratio $1,5 \mathrm{~kg}$ de tourteaux de colza substitués à $1 \mathrm{~kg}$ de tourteaux de soja. Concernant les animaux monogastriques, la formulation des aliments composés fixe des limites maximales $d$ 'incorporation, sévères dans certains cas, du tourteau de colza en fonction de sa composition et de ses caractéristiques nutritionnelles. Les limites moyennes pratiquées par les fabricants figurent au tableau 5.

\section{Tourteau de tournesol}

La consommation française de tourteaux de tournesol se situe, en 2004, entre 700000 et 750000 t, dont 690000 t incorporées dans les aliments composés par les fabricants d'aliments du bétail ( $F A B)$. Les usages en fabrication d'aliments à la ferme sont actuellement limités. Concernant les aliments composés, on estime que $85 \%$ des tourteaux sont non décortiqués (" pailleux ») et $15 \%$ partiellement décortiqués (tableau 1) essentiellement importés, mais aussi produits en France (Auvergne Trituration). Les taux moyens d'incorporation figurent au tableau 6.

\section{Des matières premières encore insuffisamment et irrégulièrement utilisées}

Une enquête réalisée en 2000 par le CEREOPA (Centre d'étude et de recherche sur l'économie et l'organisation des productions animales) auprès de 11 firmes services et de 36 fabricants d'aliments, représentant un volume d'aliments composés de 16 millions de tonnes (soit plus de $70 \%$ de la production française), révélait des niveaux très variables d'utilisation des tourteaux de colza et de tournesol (tableau 7)

Les principales raisons justifiant les limites $d^{\prime}$ incorporation du tourteau de colza étaient : - concernant les porcs : des problèmes d'inappétence et la présence de facteurs antinutritionnels (72\% des réponses);

- concernant les volailles : la présence de facteurs antinutritionnels, des problèmes d'inappétence et de goût des œufs (70 \% des réponses);

- concernant les vaches laitières: des problèmes d'inappétence (72 \% des réponses).

Les principales raisons justifiant les limites d'incorporation du tourteau de tournesol étaient :

- concernant les porcs : taux de cellulose élevé, variabilité de la qualité (52\% des réponses);

- concernant les volailles: taux de cellulose élevé, variabilité de la qualité (53\% des réponses);

- concernant les vaches laitières : variabilité de la qualité et problèmes de granulation (45\% des réponses).

Cette irrégularité traduit à la fois la persistance de freins techniques, notamment chez les monogastriques, et une mauvaise connaissance des tourteaux.

Cette étude indique donc que des marges de progrès dans l'utilisation de ces matières premières sont possibles, d'abord par une meilleure connaissance des zones de risques et des conditions d'emploi - ceci est surtout valable pour les tourteaux de colza dont la valeur énergétique et le contenu en glucosinolates résiduels après trituration des graines sont déterminants en formulation pour fixer les limites maximales d'incorporation - ensuite par des gains de qualité supplémentaires susceptibles d'être apportés aux graines oléagineuses, colza notamment. À cet égard, une étude de simulation récente (2004) du CEREOPA indi-

Tableau 7. Limites d'incorporation en usage chez les $F A B$.

\begin{tabular}{|lcc|}
\hline & Porcs charcutiers (\%) & Poulets de chair (\%) \\
\hline Tourteaux de colza & 4 à 15 & 0 à 10 \\
Tourteaux de tournesol & 3 à 12 & 3 à 10 \\
\hline
\end{tabular}


que qu'une augmentation de $50 \%$ des limites $d^{\prime}$ incorporation des tourteaux de colza se traduirait par une progression de $18 \%$ de la consommation de ces tourteaux (toutes espèces animales confondues).

Ce résultat, issu du modèle Prospective Aliment doit évidemment être modulé dans la mesure où d'autres contraintes sont déterminantes pour le choix d'une matière première et ses limites d'incorporation comme la digestibilité des protéines (acides aminés limitants), le tonnage d'aliments produits, la localisation des usines et le type d'élevages auxquels s'adresse le fabricant.

\section{RÉFÉRENCES}

BARRE P. Rations protéiques: répondre aux nouvelles contraintes. Oléoscope $1998 ; 14: 10-3$.

BURGHART P, EVRARD J. Craines oléagineuses: du stockage à l'alimentation animale. Les points techniques du CETIOM. 2002.

EVRARD J. Mieux valoriser les protéines d'oléagineux. Oléoscope 1998 ; 44 : 14-7.
EVRARD J. Les modèles d'alimentation animale. Oléoscope $2004 ; 79$ : 9-24.

COLLECTIF. De la production à la consommation, 2004-2005. PROLEA, Statistiques des Oléagineux \& Protéagineux \& Huiles \& Protéines Végétales.

LAPIERRE O, PRESSENDA F. Etude des voies d'amélioration de la qualité des graines et tourteaux de colza destinés à l'alimentation animale. Rapport final interne, CEREOPA. 2004.

SAUVANT D, PEREZ J-M, TRAN G. INRA, Tables de composition et de valeur nutritive des matières premières destinées aux animaux d'élevage. 2004. 